\title{
O PROCESSO DE BOLONHA E A GLOBALIZAÇÃO DA EDUCAÇÃO SUPERIOR: ANTECEDENTES, IMPLEMTAÇÃO E REPERCUSSÕES NO QUE FAZER DOS TRABALHADORES DA EDUCAÇÃO
}

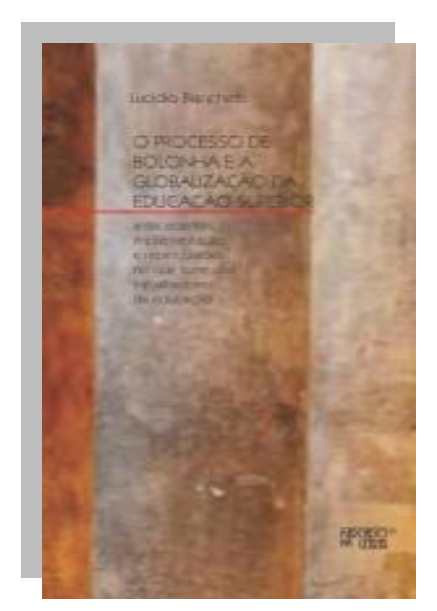

\author{
BIANCHETTI, Lucídio. O processo de Bolonha e a \\ globalização da educação superior: antecedentes, \\ implementação e repercussões no que fazer dos \\ trabalhadores da educação. Campinas, SP: Mercado de \\ Letras, 2015.
}

\section{Silvia Regina Canan ${ }^{1}$}

A resenha em tela traz considerações da obra intitulada "O processo de Bolonha e a globalização da educação superior: antecedentes, implementação e repercussões no que fazer dos trabalhadores da educação", escrita por Lucídio Bianchetti e publicada pela Editora Mercado de Letras, no ano de 2015. ${ }^{2}$ Conhecido pesquisador brasileiro, Bianchetti traz nesse livro importantes reflexões sobre o Processo de Bolonha e suas repercussões na Educação Superior europeia. Fruto de seus estudos pós-doutorais, realizados junto à Faculdade de Psicologia e Ciências da Educação da Universidade do Porto - Portugal, com apoio da Capes, desenvolveu o projeto: "Pesquisadores sob pressão: aproximações entre as exigências do modelo Capes de avaliação e fomento e o Processo de Bolonha e as decorrências para o trabalho dos pesquisadores em Educação.” Através da metodologia de estudos comparados, o autor propôs-se a estabelecer pontos que pudessem aproximar a estruturação da Capes enquanto órgão de formação de professores e pesquisadores que avalia e financia a pesquisa no Brasil (tendo como mote a pós-graduação stricto sensu) e o Processo de Bolonha, no âmbito da União Europeia, a partir da instituição da Declaração ou Processo de Bolonha, datada de 1999.

\footnotetext{
${ }^{1}$ Universidade Regional Integrada do Alto Uruguai e das Missões. E-mail: Silcanan44@gmail.com - ORCID: http://orcid.org/0000-0003-4504-3680.

${ }^{2}$ A versão em Espanhol da obra, "El proceso de Bolonia y la globalización de la educación superior: antecedentes, implementación y repercusiones en el quehacer de los trabajadores de la educación", foi publicada, em formato e-book, no ano de 2016 pelo Consejo Latinoamericano de Ciencias Sociales (CLACSO), no Repositorio Digital de CLACSO - Red de Bibliotecas Virtuales de Ciencias Sociales de America Latina Y El Caribe, através do sitio http://biblioteca.clacso.edu.
} 
A obra aqui apesentada foi construída em quatro capítulos intitulados: "Contexto deste texto e sua delimitação à guisa de apresentação"; Do político e econômico-financeiro na União Europeia, ao cultural educacional"; Emergência do Processo de Bolonha e a reconstrução da universidade europeia"; Reestruturação econômica, política e social da União Europeia: a 'estratégia de Lisboa' e o Processo de Bolonha", finaliza com: "A título de conclusão". O livro também é prefaciado por Jorge Olímpio Bento em texto cujo título é: "Processo de Bolonha: uma ofensa e traição à ideia e missão da universidade".

O prefácio, escrito pelo Professor Catedrático e Diretor da Faculdade de Desporto da Universidade do Porto, Jorge Olímpio Bento, desenvolve uma análise crítica sobre o Processo de Bolonha, posicionando-se contra ele através de argumentos contundentes que mostram os impactos daquele na missão da Universidade, a qual deixa de ter como referência a sociedade para atender ao mercado. Sua manifestação traz a leitura de quem vive o processo e assiste ao desmonte das universidades que perdem sua autonomia e identidade citando como ameaças e transformações, patrocinado pelo Processo de Bolonha, as seguintes questões: "a) subjugação da Universidade aos interesses ultraliberais e à lógica do mercado e concomitante perda de autonomia; b) proletarização e burocratização esterilizante dos docentes universitários; c) abandono da missão e visão humanista e da reflexão filosófica; d) ataque à erudição, ao pensamento e à razão; e) degradação dos títulos e graus acadêmicos. $\mathrm{O}$ autor destaca que o Processo de Bolonha entregou a Universidade aos ditames e interesses do mercado o qual prima pelo trabalho flexível, barato, com carga horária elevada e baixos salários. Encerra citando Raquel Varela: "Tempos houve em que a Igreja ocupava lugar central nas cidades. Hoje esse lugar é ocupado por um banco. Espero que um dia seja ocupado por uma universidade". (p.15).

$\mathrm{Na}$ apresentação do livro, Lucídio Bianchetti contextualiza o espaço em que foi desenvolvida a pesquisa, justificando-a a partir de sua trajetória de estudos no campo da pósgraduação, utilizando como metodologia os estudos comparados, em que buscou pontos de aproximação entre a estruturação da Capes no campo da formação de professores e pesquisadores, avaliação e financiamento da pesquisa no Brasil e o Processo de Bolonha, na União Europeia, inicialmente, mais voltado à graduação. Destaca que embora sejam iniciativas com inúmeros elementos que as distanciam, em especial em relação ao estatuto jurídico, existem muitos pontos de aproximação. No que se refere às similaridades, o destaque vai para "à imposição de um modelo de avaliação, de novas formas de financiamento e controle/regulação, com forte poder indutivo, instituinte, que põem em questão um dos aspectos mais prezados e centrais na constituição histórica e na atuação da universidade: sua economia". (p.23)." Destaca que a pesquisa avançou para além das questões, inicialmente pensadas, e investigou as repercussões do Processo de Bolonha na produção e veiculação do conhecimento na saúde/trabalho dos investigadores europeus, 
traçando um paralelo entre a realidade brasileira e a de países da União Europeia. ${ }^{3}$ Considerando que o Processo de Bolonha também foi sendo globalizado e seus reflexos estão cada vez mais explícitos no Brasil e na América Latina. Os contornos de uma "agenda globalmente estruturada" em torno da educação tornaram-na mais concreta e exigiram, também, maiores leituras dos documentos dos organismos multilaterais, onde essas propostas de agenda estão sintetizadas. Afirma que "para adentrar a esse complexo processo é preciso apreender como a universidade pública está sendo assimilada, diluída, "desprestigiada" (BUEY, 2009), subsumida aos ditames do chamando "capitalismo acadêmico" ou "academic capitalismo" (Paraskeva, 2009; Stlaughter e Rhoades, 2004) ou ao novo "managerialismo" (SANTIAGO et al, 2005) ou ainda sendo vítima de uma "ofensiva do internacionalismo acadêmico de base mercantil”. (SANTOS; ALMEIDA FILHO, 2008).”

O capítulo intitulado "Do político e econômico-financeiro na União Europeia, ao cultural e educacional" traz a perspectiva de elucidar os aspectos relacionados à gênese da concepção do Processo de Bolonha, mostrando como se deu sua implantação na União Europeia, com destaque para os primeiros desdobramentos, adesões, resistências, abrangência e perspectivas. Nesse viés, destaca que, a partir do acordo, a universidade vem se transformando e perdendo sua autonomia, tendo assumido atribuições que estiveram distantes do espaço universitário por centenas de anos. Conforme destaca Bianchetti (2015, p.29): "Dentre as mudanças mais recentes da universidade contabiliza-se o refluxo das características do modelo humboldiano e do pouco que se conseguiu avançar em termos de imprimir à universidade um caráter republicano, somando-se o fato de que a educação vem passando, gradativamente, de um preconizado bem público para um concreto produto privado, para não se falar em uma commodity a ser intercambiada entre mercados." Diante desse cenário é possível, como muito bem nos aponta o autor, que os proponentes do Processo de Bolonha, embora conscientes de que a iniciativa desse documento fosse ambiciosa, não poderiam imaginar a dimensão mundial que ele tomaria.

O capítulo seguinte discorre sobre a "Emergência do processo de Bolonha e a reconstrução da Universidade Europeia", em que o autor explicita elementos históricocontextuais na expectativa de compreender o que levou a União Europeia a "apropriar-se dessa estratégia de reconstrução de suas universidades." (p.39). A reconstrução pauta-se no desafio de inserir o Continente na sociedade e economia do conhecimento para a criação do Espaço Europeu de Ensino Superior. O contexto retrata que a Europa, que, historicamente, exerceu hegemonia em todos os campos, no que se convencionou chamar de visão "eurocêntrica" (p. 41) vinha perdendo espaço em especial por conta de movimentos nacionalistas que provocaram guerras, devastações e, por consequência, perda do protagonismo da Europa em nível mundial. No aspecto econômico a Europa trabalhou com a

\footnotetext{
${ }^{3}$ Embora a pesquisa tenha essa amplitude, neste livro, o autor trouxe uma leitura que envolveu o campo teórico, por proposta editorial. Nesse caso, os dados comparativos, resultante da pesquisa empírica, não constam dessa produção.
} 
unificação em torno do Euro como moeda única da organização de um mercado comum, a fim de que os estados se tornassem mais competitivos, tendo a União Europeia emergido no bojo da globalização, numa resposta ao temor que a Europa acalentava de vir a ser colonizada pelos Estados Unidos. (DIAS SOBRINHO, 2009). Inúmeros programas no campo da educação e da cultura são criados, sempre na perspectiva de recuperar espaços e buscar novas conquistas no jogo da globalização. Essa busca de recuperação de espaços é que conduz a União Europeia a lançar seu projeto de globalização da educação superior, entrando num mercado competitivo, disputando o mercado do ensino superior. Citando Robertson (2009), Bianchetti salienta que a educação superior passa a ser utilizada como uma plataforma para as estratégias de afirmação da União Europeia e de sua globalização.

A seguir, o autor traz o capítulo "Reestruturação econômica, política e social da União Europeia: a "estratégia de Lisboa" e o Processo de Bolonha, no qual discorre, inicialmente, sobre a reunião ocorrida em Lisboa no ano de 2000, em que o Conselho Europeu acorda sobre a Estratégia ou Tratado de Lisboa, através do qual se coloca em pauta um "amplo processo de reestruturação econômica, política e social, no sentido de impulsionar o desenvolvimento econômico dos países em particular e da União Europeia em geral, propondo criar mais e novos empregos, discutir e implementar as mudanças necessárias para os "Estados Unidos da Europa" melhorarem sua estrutura social e sua capacidade competitiva na cada vez mais globalizada "Economia do Conhecimento". (p.53). Segundo disserta o autor, a Estratégia de Lisboa nasce em decorrência do Processo de Bolonha, que segundo Robertson (2009), citada pelo autor "A estratégia de Lisboa confirmou uma compreensão neoliberal da contribuição da educação superior para o bem-estar econômico da região: a reconstrução e retenção do capital humano.” (p.58). Está claramente pautado nesta obra que o Processo de Bolonha contribuiu para que um patrimônio histórico-cultural da humanidade, neste caso a universidade, tenha sido conduzido à submissão dos ditames do mercado. No que se refere ao ensino superior, os organismos internacionais, através de seus diagnósticos e prognósticos desempenham um papel fundamental na instrumentalização dos governos sobre as melhores estratégias, exigindo mudanças para que a instituição se adequasse aos novos tempos, dando sua contribuição para que a Europa alcançasse, de fato, um lugar de destaque.

O autor chama atenção para o ano de 1988 quando, por ocasião do centenário da Universidade de Bolonha, reitores de universidades europeias assinaram a Magna Charta Universitatum em que se colocavam como guardiões da secular instituição em tempo em que iniciativas cada vez mais ousadas, por parte de empresários, tentavam transformar a universidade numa empresa. O teor dessa carta reafirmava o desejo em relação à universidade, mas suas intensões hoje, já fazem parte do passado, porque a Universidade nunca mais será a mesma. Dez anos depois em 1998, foi publicada a Declaração de Sorbone, em comemoração ao $8^{\circ}$ centenário da Universidade de Paris, neste ato e nos atos seguintes que se repetiram a cada dois anos, todas foram assinadas pelos Ministros da Educação e não mais pelos Reitores. Mencionando Garcia (2008) o autor nos mostra que "Os ministros, além de elogios à universidade, explicitam a necessidade de que ela seja (meta)avaliada, que dê sua

\begin{tabular}{l|l|l|l|l|l|l} 
(c) Rev. Inter. Educ. Sup. & Campinas, SP & v.3 & n.1 & p.240-244 & jan./abr. 2017 & ISSN 2446-9424 \\
\hline
\end{tabular}


contribuição para a construção europeia e já apontam para a necessária harmonização dos diplomas por parte de todas as instituições." (p.62). A entrada dos ministros da educação retira a discussão de dentro da Universidade e coloca o ensino superior dentro dos assuntos do Estado, neste caso da União Europeia. Muitas foram as questões que envolveram o processo de Bolonha. No caso dessa pesquisa que entrevistou 16 professores encarregados de "fazer Bolonha funcionar", ao visitar diferentes universidades de seis diferentes países, paralelo às críticas ao Processo de Bolonha, está também a constatação de que ele está implementado e nos seus parâmetros gerais tem avançado de forma célere. Ao instituir o Processo de Bolonha não houve o envolvimento de alunos e de professores. Mencionando Ruiz (2004), Bianchetti esclarece:“A Declaração de Bolonha pode ser considerada um documento base, uma carta de princípios, uma espécie de constituição bastante enxuta, a qual, à proporção que veio colocada em prática, fez-se seguir de iniciativas que ratificam ou retificam os princípios originários dessa considerada a mais importante decisão na área educacional, por parte da Europa, nos últimos cem anos". (p.102).

O texto do livro, ainda que brevemente, mostra os grandes esforços empreendidos para a construção de um "Modelo Europeu de Universidade" e, neste processo, a presença do Bologna Follow-up Group (grupo formado por funcionários de alta qualificação designados para fazer o acompanhamento do Processo de Bolonha) é marcante.

\section{Para finalizar}

A totalidade da obra proporciona não somente compreender o que é, como foi construído e como vem sendo implementado o Processo de Bolonha no âmbito dos países Europeus, como esclarece o quanto o mundo da educação e do trabalho tem sido permeado pelas relações entre a universidade e a empresa, tendo sido, essa, uma das marcas mais importantes do Processo de Bolonha, que trouxe para o campo educacional a presença cada vez mais marcante dos organismos internacionais, das empresas e dos governos. Nesse sentido, o livro alerta-nos para o fato de a universidade estar sendo cada vez mais demandada e convidada a suprir as necessidades do, sempre em mudança, mercado de trabalho. Como bem nos esclarece Bianchetti (2015, p. 111): "Nesses documentos, fica explícito o quanto o papel da universidade veio sendo readaptado a objetivos que pouca relação guardam com as funções históricas da instituição universitária." E avança dizendo (Id, p. 118) "A universidade de cariz humboldiano, da livre investigação, da autonomia da instituição, da liberdade de ensino, pesquisa, extensão e aprendizagem por parte de professores e discentes, é parte mais de uma aposta do final do século XIX, que deu alguns passos e gerou tantas expectativas na direção de sua concretização no decorrer do século XX. Esta universidade está no fim ou já não existe.” Esse é parte do panorama apontado pelo livro que é de leitura profunda e esclarecedora. 